J. Math. and Its Appl.

E-ISSN: 2579-8936

P-ISSN: $1829-605 \mathrm{X}$

Vol. 15, No. 1, Maret 2018, 31-40

\title{
Analisis Kestabilan Model Penurunan Sumber Daya Hutan
}

\section{Akibat Industri}

\author{
Indira Anggriani ${ }^{1}$, Sri Nurhayati ${ }^{2}$, Subchan $^{3}$ \\ ${ }^{1,2}$ Institut Teknologi Kalimantan, Balikpapan \\ email: indira.anggriani@itk.ac.id \\ ${ }^{3}$ Institut Teknologi Sepuluh Nopember, Surabaya \\ email: subchan@matematika.its.ac.id
}

\begin{abstract}
Abstrak
Pertumbuhan populasi penduduk karena perkembangan industri di Indonesia memberikan dampak negatif terhadap sumber daya hutan. Pada penelitian ini bertujuan untuk menganalisis kerusakan hutan dengan adanya pengaruh laju pertumbuhan penduduk karena faktor migrasi penduduk. Permasalahan tersebut kemudian diformulasikan ke dalam bentuk model matematika dan dianalisis kestabilan sistemnya. Persamaan model matematika ini merupakan sistem persamaan diferensial nonlinier. Kestabilan sistem diperoleh dengan menganut kriteria Routh-Hurwitz. Selanjutnya, dari titik kesetimbangan yang diperoleh dilakukan simulasi numerik. Pada hasil numerik menunjukkan terjadinya peningkatan kesetimbangan dari populasi penduduk dan industrialisasi yang mengakibatkan tingkat kesetimbangan biomassa hutan mengalami penurunan. Populasi memiliki dampak besar terhadap ekologi stabilitas sehingga dilakukan pengendalian terhadap pertumbuhan populasi atau untuk melindungi sumber daya hutan dari kepunahan.
\end{abstract}

Katakunci: Analisis Kestabilan, Sumber Daya Hutan, Industri

\begin{abstract}
Population growth due to industrial development in Indonesia has a negative impact on forest resources. In this study aims to analyze the damage to the forest with the influence of population growth due to migration. The problem was then formulated into a mathematical model and analyzed the stability of the system. The equation of this mathematical model is a system of nonlinear differential equations. The stability of the system is obtained by adopting the criteria of Routh-Hurwitz. Furthermore, from the equilibrium point obtained numerical simulation. The numerical results indicate an increase in equilibrium of the population and industrialization resulting in a decline in forest biomass equilibrium. The population has a major impact on the ecology of stability so as to control population growth or to protect forest resources from extinction.
\end{abstract}

Keywords: Analysis of Stability, Forest Resources, Industry

\section{Pendahuluan}

Hutan merupakan sumber daya yang sangat penting keberadaannya bagi makhluk hidup.

Sumber daya hutan merupakan sumber daya alam yang memiliki peranan penting dalam 
kehidupan dari berbagai aspek. Penebangan hutan yang terjadi seperti perluasan lahan, penggundulan hutan, dan terkait industrialisasi yang tidak diimbangi dengan regenerasi hutan menyebabkan penurunan kualitas sumber daya hutan.

Indonesia termasuk salah satu negara di dunia yang memiliki luas hutan alam yang terluas di dunia. Kekayaan sumber daya hutan menyebabkan masyarakat menggantungkan hidup dan mata pencahariannya dari hutan, seperti mengumpulkan berbagai jenis hasil hutan untuk memenuhi kebutuhan hidup. Indonesia merupakan negara dengan kepadatan penduduk yang tinggi sehingga tingginya tingkat pertumbuhan penduduk disertai pertambahan penduduk akibat migrasi menuntut lahan pekerjaan yang luas. Hal tersebut, menyebabkan semakin banyak alih guna lahan untuk kawasan perindustrian, perumahan, maupun infrastuktur penunjang lainnya. Mengingat bahwa kapasitas hutan yang terbatas untuk memenuhi kebutuhan manusia, sehingga dapat terjadi penebangan pohon secara besar untuk memenuhi kebutuhan hidup. Dengan demikian, semakin tingginya populasi manusia dan tekanan akibat pertumbuhan penduduk menjadikan kawasan hutan saat ini mengalami penipisan. Pada akhirnya, hutan memiliki kemungkinan terjadi kepunahan. Berdasarkan permasalahan tersebut, dapat disimpulkan bahwa terdapat keterkaitan antara degradasi hutan yang diprakarsarai oleh kepadatan penduduk dan kepadatan industrialisasi [1].

Pengembangan ilmu di bidang matematika turut memberikan peranan penting dalam mencegah masalah ekologi. Penelitian pertama Dubey dkk mempelajari masalah efek industrialisasi dan populasi terhadap hutan [2]. Pada tahun 2010, Dubey dan Narayana mengemukakan model matematika mengenai pengaruh industrialisasi, populasi, dan polusi terhadap pengurangan sumber daya terbaharui [3]. Pada model yang dikemukakan oleh Dubey, dkk., dijelaskan mengenai pengaruhnya penipisan kawasan hutan yang disebabkan bertambahnya industrialisasi terhadap tekanan kepadatan populasi (tekanan pertumbuhan penduduk yang sangat signifikan). Model tersebut menggambarkan sumber daya hutan yang akan menuju kepunahan seiring bertambahnya sektor industri, sehingga dibutuhkan langkah pencegahan pada pertumbuhan industri [4]. Menganut pada penelitian Dubey, dkk., penelitian terbaru telah dikemukakan oleh V. Ramdhani, Jaharuddin, E. H. Nugrahani dengan melihat kepadatan industrialisasi dan penambahan kontrol pada kepadatan industri [5].

Berdasarkan penelitian yang dikemukakan oleh Ramdhani, dkk. kemudian dilakukan rekontruksi model dengan mempertimbangkan faktor migrasi sebagai pertambahan penduduk. Permasalahan tersebut kemudian diformulasikan ke dalam bentuk model matematika dan dianalisis kestabilan sistemnya. Analisis kestabilan yang dilakukan dengan menggunakan analisis kestabilan lokal yang bertujuan untuk mengetahui kestabilan di sekitar titik 
kesetimbangannya. Hasil dari analisis kestabilan kemudian dilakukan simulasi numerik sehingga dapat diketahui perubahan sumber daya hutan terhadap kepadatan populasi manusia dengan adanya sektor industri.

\section{Formulasi Penurunan Sumber Daya Hutan}

Pada bab ini akan dijelaskan mengenai asumsi yang digunakan dan pembentukan model matematika analisis kestabilan penurunan sumber daya hutan akibat industri.

\subsection{Asumsi Model Matematika}

Asumsi yang digunakan pada model matematika analisis kestabilan penurunan sumber daya hutan akibat industri adalah:

1. Kepadatan sumber daya hutan dan populasi manusia berbentuk persamaan logistik.

2.Pertambahan penduduk berupa migrasi dipengaruhi oleh industrialisasi.

3. Penurunan sumber daya hutan merupakan efek dari peningkatan populasi manusia dan industrialisasi.

4. Tekanan populasi penduduk sebagai akibat dari kepadatan penduduk.

5. Sektor industri terfokus pada penggunaan hasil hutan secara langsung dan bangunan penunjang lainnya.

\subsection{Model Matematika}

Model matematika dari permasalahan hutan ini melibatkan empat variabel, yaitu biomassa sumber daya hutan $(B)$, populasi penduduk $(N)$, tekanan kepadatan penduduk $(P)$, dan industrialisasi $(I)$ maka dapat diformulasikan dalam persamaan sistem berikut:

$$
\begin{aligned}
& \frac{d B}{d t}=s\left(1-\frac{B}{L}\right) B-s_{0} B-\beta_{2} N B-s_{1} I B-\beta_{3} B^{2} I_{p} \\
& \frac{d N}{d t}=\gamma\left(1-\frac{N}{K}\right) N-\gamma_{0} N+\beta_{1} N B+Q_{0} N I_{y} \\
& \frac{d P}{d t}=\lambda N-\lambda_{0} P-\theta I_{y} \\
& \frac{d I}{d t}=\pi \theta P+\pi_{1} s_{1} I B-\theta_{0} I .
\end{aligned}
$$

dengan:

$\boldsymbol{s} \quad$ : laju pertumbuhan intrinsik sumber daya hutan

$\boldsymbol{s}_{0} \quad$ : laju kerusakan alami sumber daya hutan

$\boldsymbol{s}_{1} \quad$ : laju kerusakan sumber daya hutan disebabkan perkembangan industri

$\boldsymbol{\pi}_{\mathbf{1}} \boldsymbol{s}_{\mathbf{1}} \quad$ : laju pertumbuhan industri disebabkan tersedianya sumber daya hutan yang memadai 


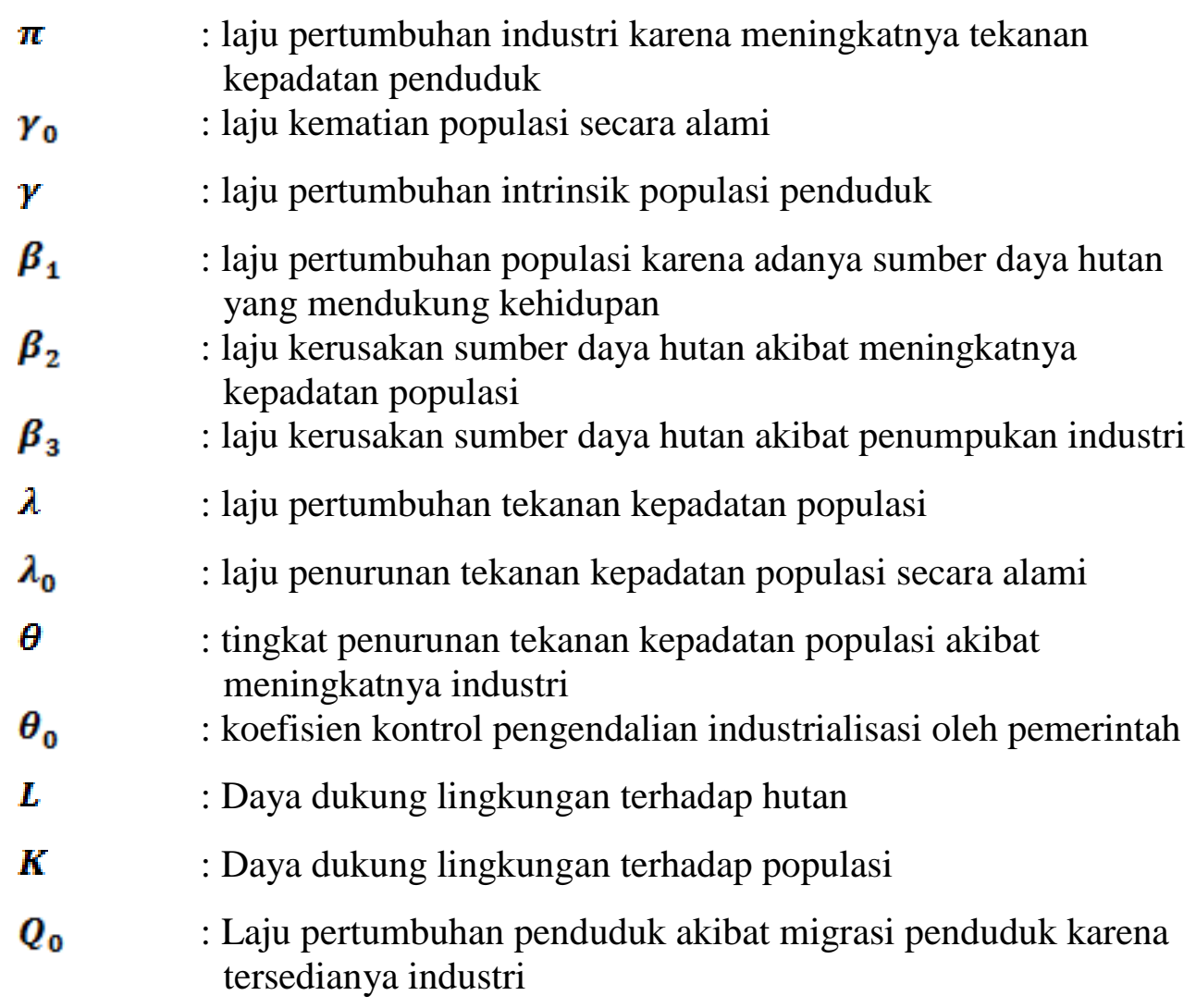

Bentuk model tersebut dinyatakan dalam bentuk persamaan diferensial tak linier, yang memenuhi kondisi awal dari setiap variabel adalah positif. $B(0) \geq 0, N(0) \geq 0, I(0) \geq 0$, dimana $\pi_{1}$ dan $\pi$ berupa peluang yang berada pada selang $0<\pi \leq 1,0<\pi_{1} \leq 1$ [5].

\section{Hasil dan Pembahasan Simulasi Penurunan Sumber Daya Hutan}

Pada bab ini akan dibahas tentang kestabilan titik kesetimbangan dan hasil simulasi numerik.

\subsection{Titik Kesetimbangan Model}

Pada subbab ini, dicari titik kesetimbangan dari model seperti pada sistem (1). Titik setimbang diperoleh ketika keadaan dari:

$$
\frac{d B}{d t}=\frac{d N}{d t}=\frac{d P}{d t}=\frac{d I}{d t}=0
$$

sehingga diperoleh sistem persamaan, yaitu:

$$
\begin{array}{ll}
s\left(1-\frac{B}{L}\right) B-s_{0} B-\beta_{2} N B-s_{1} I B-\beta_{3} B^{2} I & =0 \\
\gamma\left(1-\frac{N}{K}\right) N-\gamma_{0} N+\beta_{1} N B+Q_{0} N I & =0 \\
\lambda N-\lambda_{0} P-\theta I & =0
\end{array}
$$




$$
\pi \theta P+\pi_{1} s_{1} I B-\theta_{0} I \quad=0
$$

Dari model tersebut dihasilkan empat titik kesetimbangan tak negatif, yaitu $E_{1}(0,0,0,0), E_{2}(\widehat{B}, 0,0,0), E_{3}(0, \bar{N}, \bar{P}, \bar{I})$, dan $E_{4}\left(B^{*}, N^{*}, P^{*}{ }_{,}^{*}\right)$. Titik kesetimbangan yang pertama $E_{1}(0,0,0,0)$ merupakan suatu kondisi dimana tidak terjadi pengaruh apapun dari adanya industri, populasi, dan tekanan kepadatan populasi terhadap keadaan hutan. Selanjutnya, akan diberikan $B^{*}, N^{*}, P^{*}$, dan $I^{*}$ sebagai berikut:

$$
\begin{aligned}
B^{*} & =\frac{L\left(s-s_{0}+\beta_{2} N^{*}-s_{1} I^{*}\right)}{\left(s+L \beta_{3} I^{*}\right)}, \\
N^{*} & =\frac{K}{\gamma}\left(\gamma-\gamma_{0}+\beta_{1} B^{*}+Q_{0} I^{*}\right), \\
P^{*} & =\frac{\lambda N^{*}-\theta I^{*}}{\lambda_{0}}, \\
I^{*} & =-\frac{\pi \theta P^{*}}{\left(\pi_{1} s_{1} B^{*}-\theta_{0}\right)} .
\end{aligned}
$$

Dari uraian dalam menetukan titik kesetimbangan di atas, selanjutnya dari setiap titik kesetimbangan yang diperoleh akan dilihat sifat kestabilannya serta jenis dari kestabilan setiap titik.

\subsection{Kestabilan Titik Kesetimbangan Model}

Titik kesetimbangan $E_{1}, E_{2}, E_{3}$, dan $E_{4}$ dianalisis menggunakan metode pelinearan. Mulamula dilakukan linearisasi sistem Persamaan (1) dengan ekspansi deret Taylor, sehingga diperoleh matriks Jacobi dari sistem persamaan tersebut. Berikutnya, dari matriks Jacobi untuk masing-masing titik kesetimbangan, dilihat jenis kestabilan berdasarkan nilai eigen dari matriks Jacobiannya. Sedangkan, untuk titik $E_{3}$ dan $E_{4}$ diterapkan kriteria Routh-Hurwitz untuk memperoleh sifat kestabilannya. Perlakuan yang diberikan pada titik kesetimbangan $E_{3}$ dan $E_{4}$ untuk menganalisis kestabilannya dikarenakan sulit untuk secara langsung mendapatkan akar dari persamaan karakteristiknya.

\subsubsection{Kestabilan Titik Kesetimbangan $\boldsymbol{E}_{\mathbf{1}}(\mathbf{0 , 0 , 0 , 0 )}$}

Linearisasi terhadap sistem persamaan (1) untuk titik kesetimbangan $E_{1}(0,0,0,0)$, dimana saat $B=0, N=0, P=0$, dan $I=0$ dihasilkan matriks Jacobi berikut [6].

$$
I_{1}=\left[\begin{array}{cccc}
s-s_{0} & 0 & 0 & 0 \\
0 & \gamma-\gamma_{0} & 0 & 0 \\
0 & \lambda & -\lambda_{0} & -\theta \\
0 & 0 & \pi \theta & -\theta_{0}
\end{array}\right]
$$


Persamaan karakteristik dari matriks Jacobi $l_{1}$ ditentukan oleh persamaan $\left|J_{1}-r \mathrm{I}\right|=0$ dimana I merupakan matriks identitas. Dengan demikian, nilai eigen $r_{1}, r_{2}$ yang diperoleh bernilai positif, sehingga titik setimbang $E_{1}$ tidak stabil. Jika $\left(-\lambda_{0}-\theta_{0}\right) \pm \sqrt{\lambda_{0}^{2}-2 \lambda_{0} \theta_{0}+\theta_{0}^{2}-4 \theta^{2} \pi}<0$ terpenuhi, maka dapat disimpulkan bahwa titik kesetimbangan $E_{1}(0,0,0,0)$ adalah tidak stabil dengan jenis saddle point atau pelana [7].

\subsubsection{Kestabilan Titik Kesetimbangan $\boldsymbol{E}_{\mathbf{2}}(\boldsymbol{B}, \mathbf{0}, \mathbf{0}, \mathbf{0})$}

Linearisasi terhadap sistem persamaan (1) untuk titik kesetimbangan $E_{2}(\widehat{B}, 0,0,0)$ dihasilkan matriks Jacobi berikut [6].

$$
I_{2}=\left[\begin{array}{cccc}
-\frac{2 s \hat{B}}{L}+s-s_{0} & -\beta_{2} \hat{B} & 0 & -s_{1} \hat{B}-\beta_{3} \hat{B}^{2} \\
0 & \gamma-\gamma_{0}+\beta_{1} \hat{B} & 0 & 0 \\
0 & \lambda & -\lambda_{0} & -\theta \\
0 & 0 & \pi \theta & \pi_{1} s_{1} \hat{B}-\theta_{0}
\end{array}\right]
$$

Persamaan karakteristik dari matriks Jacobi $J_{2}$ ditentukan oleh persamaan $\left|J_{2}-r \mathrm{I}\right|=0$ dimana I merupakan matriks identitas. Selanjutnya, diperoleh nilai eigen $r_{1}, r_{2}$ yang diperoleh bernilai positif sehingga titik setimbang $E_{2}(\hat{B}, 0,0,0)$ tidak stabil. Jika $\left(\pi_{1} s_{1} \hat{B}-\theta_{0}-\lambda_{0}\right) \pm\left(\left(\pi_{1} s_{1} \hat{B}\right)^{2}-2\left(\pi_{1} s_{1} \hat{B} \theta_{0}-\pi_{1} s_{1} \hat{B} \lambda_{0}+\theta_{0} \lambda_{0}+\right.\right.$ $\left.\left.2 \theta^{2} \pi\right)+\theta_{0}^{2}+\lambda_{0}^{2}\right)^{\frac{1}{2}}<0$

terpenuhi, maka dapat disimpulkan bahwa titik kesetimbangan $E_{2}$ adalah tidak stabil dengan jenis stabil pelana atau saddle point [7].

\subsubsection{Kestabilan Titik Kesetimbangan $\boldsymbol{E}_{3}(\mathbf{0}, \boldsymbol{N}, \boldsymbol{P}, \boldsymbol{I})$}

Linearisasi terhadap sistem persamaan (4.1) untuk titik kesetimbangan $E_{3}(0, \bar{N}, \bar{P}, \bar{I})$ dihasilkan matriks Jacobi berikut [6].

$$
I_{3}=\left[\begin{array}{cccc}
s-s_{0}-\beta_{2} \bar{N}-s_{1} \bar{I} & 0 & 0 & 0 \\
\beta_{1} \bar{N} & \gamma\left(1-\frac{2 \bar{N}}{K}\right)-\gamma_{0}+Q_{0} \bar{I} & 0 & Q_{0} \bar{N} \\
0 & \lambda & -\lambda_{0} & -\theta \\
\pi_{1} s_{1} \bar{I} & 0 & \pi \theta & -\theta_{0}
\end{array}\right]
$$

Persamaan karakteristik dari matriks Jacobi $I_{3}$ ditentukan oleh persamaan $\left|J_{3}-r \mathrm{I}\right|=0$ dimana I merupakan matriks identitas. Persamaan karakteristik dapat ditulis sebagai berikut: $a_{0} r^{4}+a_{1} r^{3}+a_{2} r^{2}+a_{3} r^{1}+a_{4} r^{0}=0$

Menurut kriteria Routh Hurwitz, titik kesetimbangan dikatakan stabil jika setiap koefisiennya bernilai sama, yaitu jika koefisien bernilai positif dimana $a_{0}>0, a_{1}>0, b_{1}=\frac{a_{0} a_{8}-a_{1} a_{2}}{a_{1}}>0$, dan $c_{1}=\frac{b_{1} a_{3}-b_{2} a_{1}}{b_{1}}>0$, hingga seterusnya. Dari perolehan nilai $a_{1}<0$ menunjukaan titik $E_{3}$ tidak stabil jika memenuhi 


$$
s+\gamma+Q_{0} \bar{I}>s_{0}+\beta_{2} \bar{N}+s_{1} \bar{I}+\frac{2 \gamma \bar{N}}{K}+\gamma_{0}+\theta_{0}+\lambda_{0}
$$

karena terjadi perbedaan tanda dimana $a_{1}$ bernilai negatif sedang $a_{0}$ positif sehingga syarat kestabilan tidak memenuhi pada titik kesetimbangan $E_{3}$. Dengan kata lain, $E_{3}(0, \bar{N}, \bar{P}, \bar{I})$ merupakan titik kesetimbangan yang tak stabil [7].

\subsubsection{Kestabilan Titik Kesetimbangan $\boldsymbol{E}_{\mathbf{4}}\left(\boldsymbol{B}^{8}, \boldsymbol{N}^{*}{ }_{3} \boldsymbol{P}_{,}{ }_{3} \boldsymbol{I}^{8}\right)$}

Sifat kestabilan titik kesetimbangan $E_{4}\left(B^{*}, N^{*}, P^{*}{ }_{3}^{*}\right)$ sulit untuk dianalisa secara eksplisit sebagaimana ketiga titik kesetimbangan sebelumnya. Itu sebabnya, dalam menentukan sifat kestabilan dari titik $E_{4}$ akan dijelaskan dengan cara yang berbeda. Sifat kestabilan dari titik kesetimbangan tersebut akan dianalisis berdasarkan kriteria Routh-Hurwitz. Hal tersebut akan dijelasakan pada uraian berikut.

Dilakukan hal yang sama seperti ketiga titik sebelumnya, yaitu dengan linearisasi terhadap sistem persamaan (1) untuk titik kesetimbangan $E_{4}\left(B^{*}, N^{*}, P^{*}, I^{*}\right)$. Sehingga diperoleh matriks Jacobi pada titik $E_{4}$ adalah

$I_{4}=\left[\begin{array}{cccc}s\left(1-\frac{2 B^{*}}{L}\right)-s_{0}-\beta_{2} N^{*}-s_{1} I^{*}-2 \beta_{2} B^{*} T^{*} & -\beta_{2} E^{*} & 0 & -B^{*}\left(s_{1}+\beta_{3} B^{*}\right) \\ \beta_{2} N^{*} & \gamma\left(1-\frac{2 N}{K}\right)-\gamma_{0}+\beta_{2} B^{*}+Q_{8} I^{*} & 0 & Q_{0} N^{*} \\ 0 & \lambda & -\lambda_{0} & -\theta \\ \pi_{1} s_{1} I^{*} & 0 & \pi \theta & \pi_{2} s_{2} B^{*}-\theta_{0}\end{array}\right]$

Nilai eigen dari matriks Jacobi $I_{4}$ ditentukan oleh persamaan $\left|J_{4}-r \mathrm{I}\right|=0$ dimana I merupakan matriks identitas. Hasil dari determinan matriks diatas dihasilkan nilai eigen dari persamaan karakterikstik yang dapat ditulis sebagai berikut:

$a_{0} r^{4}+a_{1} r^{3}+a_{2} r^{2}+a_{3} r^{1}+a_{4} r^{0}=0$

Semua akar tersebut bernilai negatif pada bagian realnya jika dan hanya jika elemen-elemen dari kolom pertama pada tabel (1) mempunyai tanda yang sama. Maka dari itu, titik $E_{4}$ bisa dikatakan stabil jika $a_{0}>0, a_{1}>0, b_{1}>0, c_{1}>0$, dan $d>0$ (Lenhart, 2007).

$$
\begin{array}{ll}
b_{1}=\frac{a_{1} a_{2}-a_{0} a_{3}}{a_{1}}, & b_{2}=\frac{a_{1} a_{4}-a_{0} 0}{a_{1}}=\frac{a_{1} a_{4}}{a_{1}}, \\
c_{1}=\frac{b_{1} a_{3}-b_{2} a_{1}}{b_{1}}, & d=\frac{b_{2} c_{1}}{c_{1}} .
\end{array}
$$

Analisis model menunjukkan terdapat empat titik kesetimbangan dari sistem, yaitu $E_{1}, E_{2}$, dan $E_{3}$ merupakan titik kesetimbangan yang tak stabil dengan jenis pelana dengan syarat kondisi tertentu yang harus tepenuhi. Selain itu, diperoleh titik $E_{4}$ yang memenuhi syarat kestabilan sehingga titik $E_{4}$ merupakan titik kesetimbangan yang stabil asimtotik. Sehingga, diperoleh titik 
kesetimbangan

$E_{4}(0.8755,4.5952,1.9147,0.0156)$

dengan

$B^{*}=0.8755, N^{*}=4.5952, P^{*}=1.9147$, dan $I^{*}=0.0156$.

\subsection{Hasil Simulasi Model}

Pada simulasi selanjutnya diidentifikasi hal-hal yang mungkin terjadi terhadap dinamika sistem. Untuk itu, pemberian variasi parameter yang digunakan dalam model pada sistem Persamaan (1) menganut nilai parameter milik Dubey dkk. tahun 2010 seperti berikut, $\bar{N}=0.424465, P=5.627588, I=0,045020709$

$L=40, K=50, Q_{0}=0.14, s=34, s_{0}=1, s_{1}=4, \gamma=11, \gamma_{0}=10, \lambda=5$,

$\lambda_{0}=4, \theta=8, \pi=0.001, \pi_{1}=0.005$

$\theta_{0}=1, \beta_{2}=7, \beta_{3}=2, \beta_{1}=0.01$.

Berdasarkan parameter yang diberikan di atas, maka diperoleh titik kesetimbangan $E_{4}\left(B^{*}, N^{*}, P^{*}, I^{*}\right)$ dengan, $B^{*}=0.8755, N^{*}=4.5952, P^{*}=1.9147$, dan $I^{*}=0.0156$. Dengan kondisi kestabilan Routh-Hurwitz terpenuhi, ini menunjukkan bahwa titik kesetimbangan $E_{4}$ adalah stabil asismtotik.

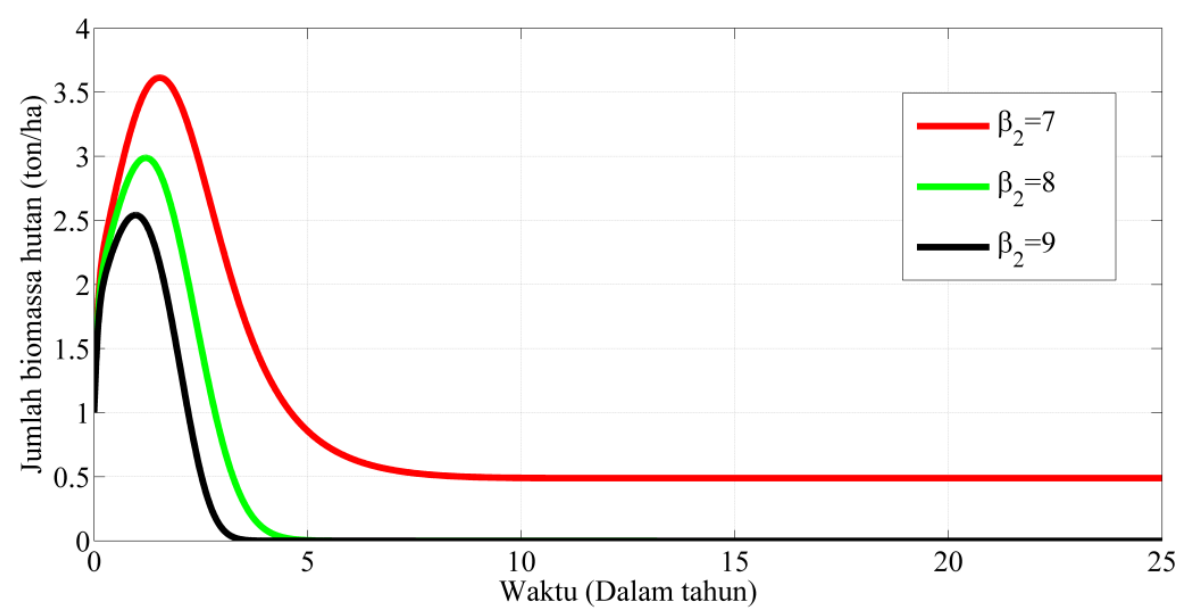

Gambar 1. Laju perubahan biomassa hutan dengan variasi parameter $\beta_{2}$

Grafik yang ditunjukkan seperti pada Gambar 1 mengalami kenaikan lalu turun hingga menuju titik setimbangnya. Kenaikan yang terjadi hingga titik puncaknya karena adanya laju pertumbuhan hutan. Laju intrinsik hutan ini bertambah lebih banyak daripada laju kematiannya $\left(\beta_{2}\right.$ dan $\beta_{3}$ ). Keadaan setimbang dari sumber daya hutan dipengaruhi dari besaran $\beta_{2}$. Semakin besar kerusakan hutan yang terjadi akibat populasi manusia maka semakin cepat hutan tersebut menuju keadaan stabilnya. 


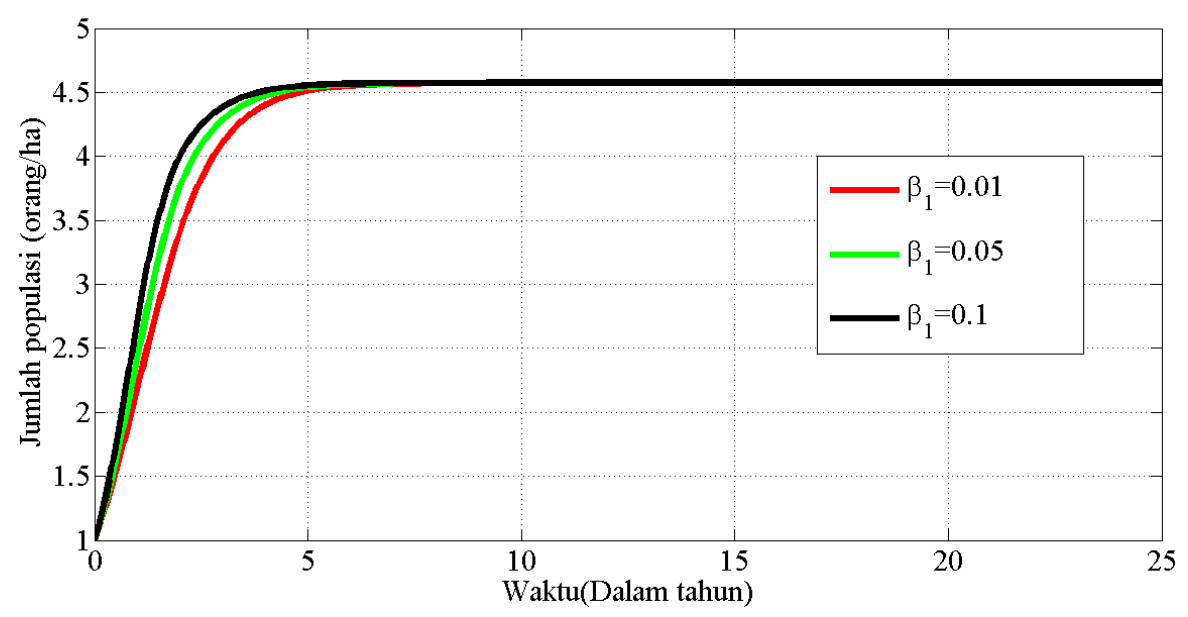

Gambar 2. Laju perubahan populasi dengan variasi parameter $\beta_{1}$

Dinamika dari populasi penduduk $N$ yang ditujukkan oleh Gambar 2 mengalami peningkatan hingga mencapai tingkat kesetimbangannya seiring peningkatan nilai $\beta_{1}$. Adanya pengaruh besaran $\beta_{1}$ yang merupakan laju pertumbuhan populasi seiring tersediannya biomassa hutan terhadap jumlah populasi penduduk. Berdasarkan tampilan Gambar 2 dapat dilihat bahwa dari model degradasi hutan mempunyai solusi yang konvergen menuju titik kesetimbangan yang sama. Hal itu berarti berapapun besarnya manusia dapat bertambah akan terbatasi dengan kondisi hutan yang memadai.

\section{Simpulan}

Berdasarkan analisis dan pembahasan yang telah disajikan pada bab sebelumnya, dapat disimpulkan bahwa:

1. Menurut analisis dari hasil simulasi, didapatkan pernyataan bahwa meningkatnya laju pertumbuhan dari populasi penduduk dan industrialisasi menyebabkan penurunan terhadap tingkat setimbang dari jumlah biomassa hutan.

2. Berdasarkan hasil simulasi, jika didapatkan kondisi kestabilan model telah terpenuhi, maka pergerakan sistem selalu menuju titik kesetimbangannya.

\section{Daftar Pustaka}

[1] S. Sundar, N. Swaroop, and R. Naresh, "Modeling the Effect of Population and Population Augmented Industrialization on Forestry Resources," Eur. J. Eng. Res. Sci., vol. 2, no. 1, p. $65,2017$.

[2] B. Dubey, S. Sharma, P. Sinha, and J. B. Shukla, "Modelling the depletion of forestry resources by population and population pressure augmented industrialization," Appl. Math. Model., vol. 33, no. 7, pp. 3002-3014, 2009. 
[3] B. Dubey and A. S. Narayanan, "Modelling effects of industrialization, population and pollution on a renewable resource," Nonlinear Anal. Real World Appl., 2010.

[4] B. Bubey, J. Hussain, S. Raw, and R. Upadhyay, "Modelling the effect of pollution on biological species: a socio-ecological problem," Comput. Ecol. Softw., vol. 5, no. 2, pp. 152-174, 2015.

[5] V. Ramdhani and E. H. Nugrahani, "Dynamical System of Modelling the Depletion of Forestry Resources Due to Crowding by Industrialization," Appl. Math. Sci., vol. 9, no. 82, pp. 4067-4079, 2015.

[6] L. Perko, Differential Equations and Dynamical Systems. 2001.

[7] S. Lenhart and J. T. Workman, Optimal Control Applied to Biological Models. 2007. 